\title{
DISPLAY PRODUK KAWASAKI MENGGUNAKAN AUGMENTED REALITY BERBASIS ANDROID
}

\author{
Avis Kurniawan \\ Program Studi Teknik Informatika S1, Fakultas Teknologi Industri \\ Institut Teknologi Nasional Malang, Jalan Raya Karanglo km 2 Malang, Indonesia \\ zafies99@gmail.com
}

\begin{abstract}
ABSTRAK
Pada saat ini, bidang industri sedang berkembang dengan pesat. Banyak perusahaan khususnya yang bergerak dibidang otomotive berlomba lomba untuk memasarkan produknya. Perkembangan tersebut dipengaruhi beberapa faktor, salah satunya adalah kebutuhan para konsumen. Produsen melakukan berbagai cara supaya para konsumen tertarik pada produknya. Umumnya produsen memasarkan produknya dengan media seperti brosur karena pertimbangan biaya yang murah, namun brosur saat ini hanya mnampilkan berupa gambar dua dimensi hal ini tentu saja membuat konsumen yang melihat brosur seperti itu merasa tidak menarik dan tidak puas karena tampilan brosur yang terbatas. Yang menjadi masalah disini adalah bagaimana menjadikan suatu informasi tersebut menjadi interaktif dan lebih menarik bagi konsumen. Dengan adanya kendala tersebut diperlukan metode pemasaran produk brosur dengan gambar 3D yang dapat membuat konsumen tertarik untuk melihat produknya dan bisa lebih detail lagi melihat tampilannya. Dalam penelitian ini Penulis yang mengambil judul "Display Produk Kawasaki Menggunakan Augmented Reality Berbasis Android" bertujuan untuk mengenalkan motode pemasaran produk menggunakan Augmented Reality berbasis android untuk menunjang pemasaran produk. Diharapkan dengan diberdayakan applikasi ini dapat membantu para produsen untuk memasarkan produknya dengan cara menampilkan produknya berupa gambar 3D menggunakan Augmented Reality.
\end{abstract}

Kata Kunci : Mobil, Augmented Reality, Android, Kawasaki

\section{PENDAHULUAN}

\subsection{Latar Belakang}

Media informasi dan teknologi selalu berkembang sesuai dengan perkembangan zaman. Banyak perusahaan yang berlomba lomba untuk menyajikan teknologi yang semakin modern dan semakin canggih terutama dalam bidang informasi.

Pada saat ini banyak perusahaan yang membutuhkan kemajuan di bidang informasi, khususnya untuk pemasaran produk yang di tawarkan kepada konsumen agar menarik perhatian konsumen terhadap produk perusahaan tersebut. Banyak perusahaan yang mempromosikan produknya hanya dengan memberikan brosur atau katalog gambar 2D. Dalam penelitian ini Penulis menyediakan solusi atau inovasi dalam pemasaran produk agar para perusahaan bisa mempromosikan produknya dengan lebih atraktif. Yakni dengan menggunakan aplikasi Augmented Reality dengan bantuan software unity3D sebagai alat bantu promosi yang mengubah gambar dalam bentuk 2D menjadi gambar 3D secara real-time, ketika produk dimunculkan secara 3D kita tidak hanya melihat produk dalam gambar 3D saja, namun kita juga bisa mendengarkan indentifikasi barang dari suara yang di keluarkan lewat pembacaan marker, kita juga bisa melihat detail struktur dalam produk tersebut dan bisa juga menganti warna-warna produk yang sudah ditentukan oleh perusahaan dan itu dilakukan bersamaan dengan penampilan produk dalam gambar 3D.

Aplikasi ini menggunakan katalog sebagai media pengidentifikasian marker yang sudah diatur untuk memunculkan produk dalam gambar $3 \mathrm{D}$, pengidentifikasian marker ini menggunakan kamera smartphone android. Dengan menggunakan Augmented Reality, konsumen akan lebih mudah untuk memahami dalam menggambarkan suatu model objek atau produk yang akan di beli.

\subsection{Rumusan Masalah}

Dari latar belakang maka dirumuskan permasalahan sebagai berikut:

1. Bagaimana cara merancang dan mengimplementasikan augmented reality pada aplikasi display produk Kawasaki menggunakan augmented reality berbasis android?

2. Bagaimana cara sistem dapat mengenali marker menggunakan smartphone berbasis android? 


\subsection{Batasan Masalah}

Dalam penyusunan skripsi agar sistematis dan mudah dimengerti, maka akan diterapkan beberapa batasan masalah :

1. Aplikasi ini di jalankan dengan bantuan kamera smartphone Android.

2. Aplikasi ini di buat dengan menggunakan software Unity3D, Vuforia, dan Android SDK.

3. Output yang dihasilkan berupa objek 3D produk mobil yang ada pada dealer Kawasaki Surapita Unitrans malang.

4. Target pengguna untuk aplikasi ini adalah custumer/pelanggan dealer Kawasaki Surapita Unitrans malang.

5. Sumber data didapat dari dealer Kawasaki Surapita Unitrans malang.

\subsection{Tujuan}

Ditinjau dari latar belakang tersebut diatas maka, tujuan penulisan skripsi ini :

1. Untuk mengimplementasikan teknologi augmented reality dalam bidang pemasaran yang akan menampilkan produk Kawasaki Surapita Unitrans malang dalam bentuk 3D berbasis android.

2. Untuk membantu Kawasaki memasarkan produknya dengan cara menampilkan produknya berupa gambar 3D dengan menggunakan teknologi augmented reality.

3. Untuk mempermudah custumer mengetahui produk yang diinginkan tanpa harus datang ke dealer Kawasaki Surapita Unitrans malang.

\section{TINJAUAN PUSTAKA}

\subsection{Penelitian Terdahulu}

Secara umum, Augmented Reality (AR) adalah suatu teknologi yang menggabungkan benda maya dua dimensi dan ataupun tiga dimensi ke dalam sebuah lingkungan nyata tiga dimensi lalu memproyeksikan benda-benda maya tersebut dalam waktu nyata. Ronald T. Azuma (1997) mendefinisikan Augmented Reality sebagai penggabungan benda-benda nyata dan maya di lingkungan nyata, berjalan secara interaktif dalam waktu nyata, dan terdapat integrasi antarbenda dalam tiga dimensi, yaitu benda maya terintegrasi dalam dunia nyata. [1]

Teknologi Augmented Reality menambah, melengkapi, atau meningkatkan realitas yang ada, dengan menambahan elemen- elemen hasil komputasi yang didapatkan dari masukan data yang bisa berupa audio, video, grafis maupun data GPS. Sedangkan Virtual Reality (VR) akan menggantikan dunia nyata atau realitas yang ada untuk disimulasikan secara penuh di komputer dalam bentuk grafis, sehingga pengguna akan merasakan dalam lingkungan yang sintetik. Dalam relasi konsep yang lebih umum augmented reality dan virtual reality merupakan suatu realitas yang termediasi (mediated reality), sebagaimana ditunjukkan seperti pada gambar 1 . [2]

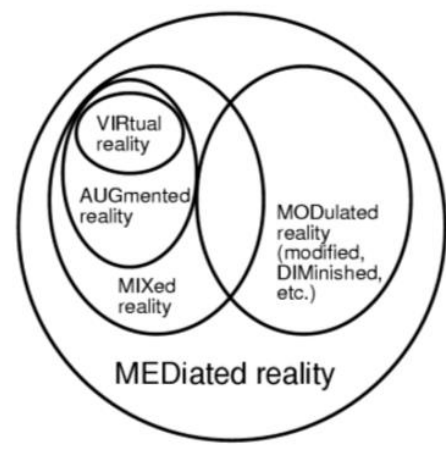

Gambar 1 Lingkungan Realistis

Terdapat dua metode pengenalan penanda pada augmented reality, yaitu; marker dan markerless. Marker merupakan penanda khusus yang dibuat seperti sebuah barcode atau bingkai hitam, sedangkan markerless merupakan penanda yang berhubungan dengan objek secara langsung. Adapun evolusi dari penggunaan marker hingga penggunaan objek nyata dalam pengenalan penanda augmented reality [3].

Untuk berinteraksi dengan buku AR yang menggunakan markerless, perlu pendekatan yang berbeda, seperti virtual button. Virtual button memungkinkan interaksi dengan objek fisik hanya dengan menyentuh objek fisik tersebut. Penerapanya dalam media buku sangat memungkinkan [4].

Augmented reality menjadi satu inovasi dalam dunia pemasaran. Pada awalnya AR digunakan untuk melengkapi pemasaran yang menggunakan media nondigital. Sampai saat ini, penggunaan teknologi Augmented reality pada bidang pemasaran masih dianggap tepat untuk khalayak berusia muda yang sangat terbuka terhadap perkembangan teknologi. Contoh kesuksesan penggunaan Augmented reality dalam komunikasi pemasaran adalah launching Nissan Altima melalui iklan dalam media cetak. Kesuksesan tersebut terlihat dari terdapat delapan juta (bahkan lebih) pembaca yang melihat iklan kampanye tersebut setiap hari, 6.500 page views, $42 \%$ click-through rate, peningkatan test drive Nissan Altima sebanyak 65\%, dan menjadi pemenang dalam penghargaan Canadian Media Awards Innovation. Di Indonesia, penggunaan Augmented reality dalam bidang komunikasi pemasaran masih belum familiar. Tetapi melihat pertumbuhan tren Augmented reality dalam komunikasi pemasaran di luar negeri, tidak 
menutup kemungkinan dalam satu tahun ke depan tren ini akan hadir di Indonesia. [5]

\subsection{DASAR TEORI}

\subsubsection{Augmented Reality}

Augmented reality merupakan penggabungan benda- benda nyata dan maya di lingkungan nyata, berjalan secara interaktif dalam waktu yang sebenarnya (real-time), dan terdapat integrasi antar benda dalam tiga dimensi, yaitu benda maya terintegrasi dalam dunia nyata. Augmented reality dapat diterapkan pada aplikasi perangkat mobile Android karena sistem pada augmented reality menganalisa secara real-time obyek yang ditangkap dalam kamera yang bisa diimplementasikan pada perangkat yang memiliki GPS, akselerometer, kompas, dan kamera. Teknologi AR ini dapat menyisipkan suatu informasi tertentu ke dalam dunia maya dan menampilkannya di dunia nyata dengan bantuan perlengkapan seperti webcam, komputer, Smartphone, maupun kacamata khusus. User ataupun pengguna didalam dunia nyata tidak dapat melihat objek maya dengan mata telanjang, untuk mengidentifikasi objek dibutuhkan perantara berupa komputer dan kamera yang nantinya akan menyisipkan objek maya ke dalam dunia nyata. [6]

\subsubsection{Android}

Android adalah sistem operasi yang berbasis Linux untuk telepon seluler seperti telepon pintar dan komputer tablet yang bersifat open source. Sistem Operasi ini diakusisi oleh Google dari perusahaan Android Inc. dan terus dilakukan pengembangan sampai sekarang. Beberapa fitur ungggulan yang terdapat dalam system operasi android (Speckmann, 2008) adalah :

1. Kerangka aplikasi: itu memungkinkan penggunaan dan penghapusan komponen yang tersedia.

2. Dalvik mesin virtual: mesin virtual yang dioptimalkan untuk perangkat telepon seluler.

3. Grafik: grafik di 2D dan grafis 3D berdasarkan pustaka OpenGL. - SQLite: untuk penyimpanan data.

4. Mendukung media: audio, video, dan berbagai format gambar (MPEG4, H.264, MP3, AAC, AMR, JPG, PNG, GIF). [7]

\subsubsection{Vuforia}

Vuforia Software Development Kit (SDK) yang dikembangkan oleh Qualcomm yang memungkinkan seorang developer untuk membuat aplikasi berbasis teknologi augmented reality. Dulu lebih dikenal dengan QCAR (Qualcomm Company Augmented reality).
Ditambah menggunakan teknologi Computer Vision untuk mengenali dan melacak gambar planar (Target Image) dan objek 3D sederhana seperti kotak secara real-time. Dengan support iOS, Android dan Unity3D, platform Vuforia mendukung para pengembang untuk membuat aplikasi yang dapat digunakan di hampir seluruh jenis smartphone. [8]

\subsubsection{Image Target}

Vuforia dapat mendeteksi beberapa jensi target, target yang digunakan disini adalah Image targets, merupakan target yang bersifat image/gambar seperti photo, game boards, halaman majalah, cover buku, brosur serta gambar-gambar lainnya. Image tracking atau image target adalah metode pendeteksian dan pelacakan target berdasarkan gambar. Tidak seperti marker tradisional seperti kode matrix atau code QR, image target Vuforia tidak membutuhkan garis hitam khusus dan daerah putih atau code untuk mengenalinya. Vuforia SDK mendeteksi dan melacak natural fitur yang ditemukan pada sebuah gambar dengan membandingkan pada gambar yang telah ditentukan didatabase. Setelah Image Target terdeteksi, maka Vuforia SDK akan melacak gambar asalkan terdapat bagian marker yang terlihat dikamera. [9]

\subsubsection{Unity 3D}

Unity adalah sebuah aplikasi yang berintegrasi dengan banyak tools dan rapid workflows yang digunakan untuk membuat konten tiga dimensi yang interaktif dan bersifat multi platform. Unity juga memungkinkan pengembang untuk membuat object, mengimport asset yang telah disediakan dari luar dan menggabungkan semuanya secara cepat dan efisien. Pengembang dapat menggabungkan beberapa script dan waktuu ntuk compile relatif cepat. Adapun fitur-fitur yang dimilik oleh Unity 3D antara lain sebagai berikut.

1. Integrated development environment (IDE) atau lingkungan pengembangan terpadu.

2. Penyebaran hasil aplikasi pada banyak platform.

3. Engine grafis menggunakan Direct3D (Windows), OpenGL (Mac, Windows), OpenGL ES (iOS), and proprietary API (Wii).

4. Game Scripting melalui Mono. Scripting yang dibangun pada Mono, implementasi open source dari NET Framework. Selain itu Pemrogram dapat menggunakan UnityScript (bahasa kustom dengan sintaks Java Script inspired), bahasa C \# atau Boo (yang memiliki sintaks Python-inspired). [10] 
3 PERANCANGAN

\subsection{Perancangan Sistem}

\subsubsection{Blok Diagram Sistem}

Perancangan blok diagram system aplikasi ini ditunjukkan pada gambar 2.

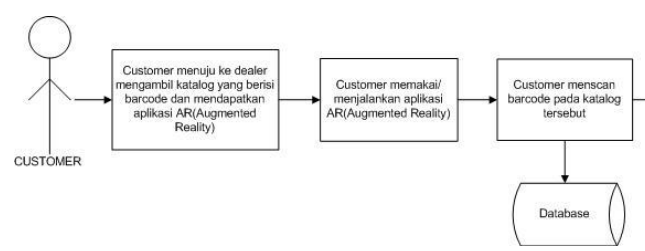

Gambar 2 Blog Diagram Sistem

Pada diagram blok sistem yang di tunjukan Gambar 2, user akan mengakses aplikasi dan aplikasi akan mengaktifkan kamera smartphone. kemudian smartphone akan membaca marker dan memberikan informasi ke user apabila marker tersebut ada pada database.

\subsubsection{Flowchart Sistem}

Flowchart system pada aplikasi Android ini ditunjukkan pada gambar 3 .

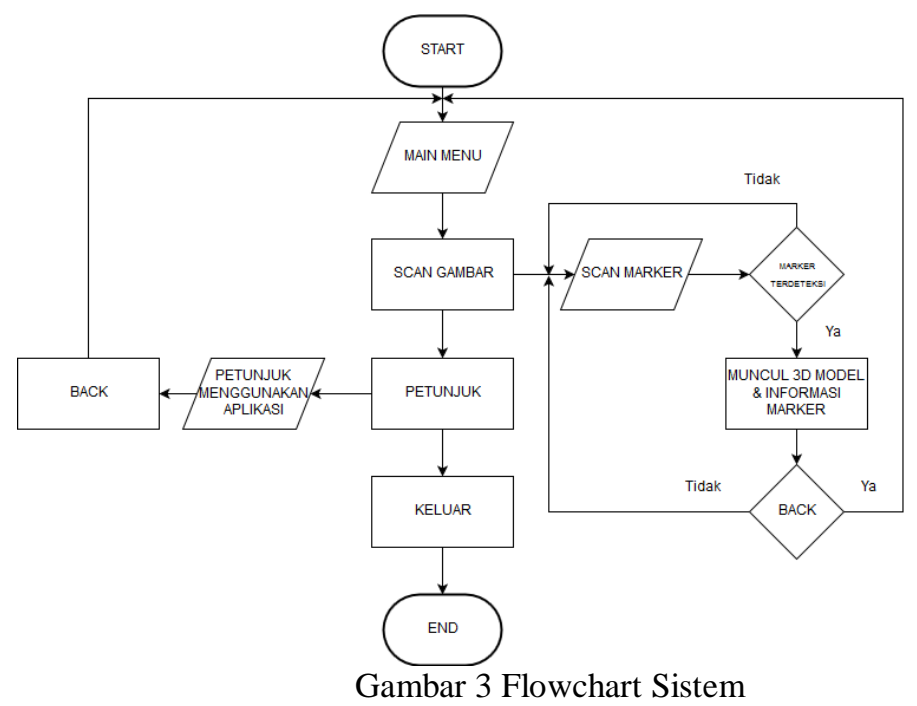

\subsubsection{Flowchart Augmented Reality}

Flowchart augmented reality pada aplikasi display produk Kawasaki ditunjukkan pada gambar 4.

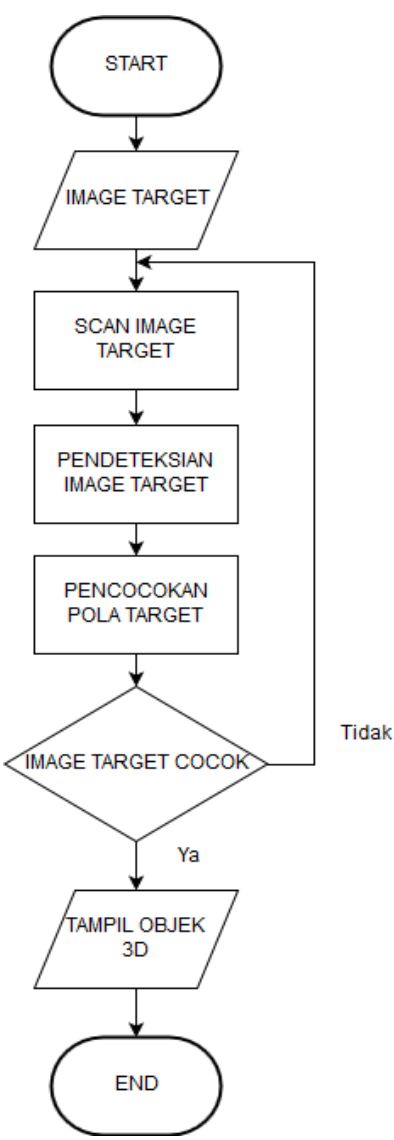

Gambar 4 Flowchart Augmented Reality

\section{IMPLEMENTASI DAN PENGUJIAN}

4.1 Implementasi Hasil

Implementasi hasil merupakan sebuah tahapan terakhir. Dalam tahap ini bagaimana tampilan yang telah di bangun. Dalam tahap implementasi ini membuat beberapa tampilan sebagai berikut.

\subsubsection{Pengujian Tampilan Awal}

Splash screen yang di tunjukkan gambar 5 merupakan tampilan awal saat pertama kali aplikasi dibuka.

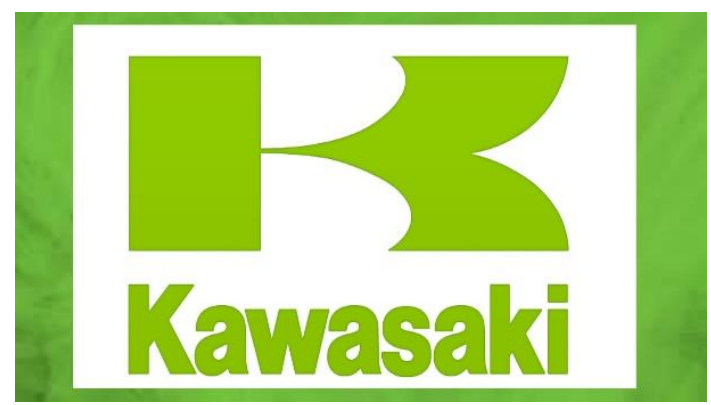

Gambar 5 Tampilan Splash screen 


\subsubsection{Pengujian Tampilan Menu Utama}

Di dalam halaman menu utama ini terdapat beberapa button yang dapat dilihat pada gambar 6 yaitu menu scan gambar, menu petunjuk, dan menu keluar.

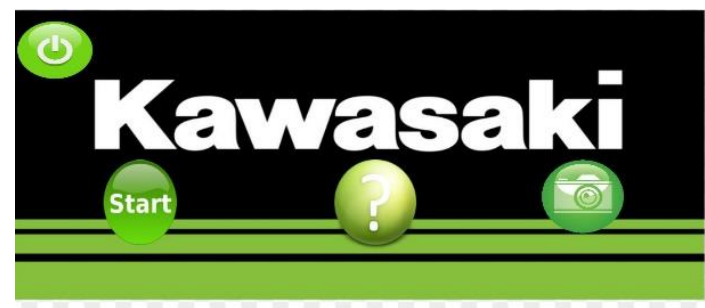

Gambar 6 Menu Utama

\subsubsection{Pengujian Tampilan Menu Scan Gambar}

Merupakan halaman dimana augmented reality diimplementasikan dan pada halaman ini diharuskan untuk menggunakan kamera smartphone, pada saat kamera smartphone dihadapkan pada marker maka objek 3D akan muncul pada layar smartphone seperti yang terlihat pada gambar 7, dan dalam halaman ini terdapat tombol back yang berfungsi untuk kembali ke halaman menu utama dan terdapat beberapa tombol lainnya seperti tombol spesifikasi untuk melihat spesifikasi dari produk dan tombol video untuk melihat video tentang produk.

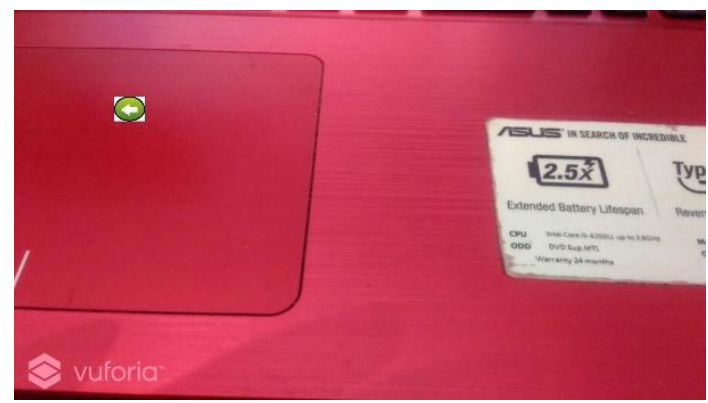

Gambar 7.Menu Scan Gambar

\subsection{Pengujian Sistem}

Pegujian adalah tahap uji coba terhadap beberapa kompnen vital di dalam sistem agar dapat di ambil kesimpulannya apakah aplikasi sudah mencapai tujuan yang di harapkan atau tidak. Pengujian terhadap beberapa komponen utama dalam sistem, yang terkait langsung dengan jalannya aplikasi pengenalan rambu lalu lintas peringatan menggunakan metode augmented reality.

\subsubsection{Pengujian Fungsional}

Pengujian fungsional adalah pengujian mengenai peroses fungsional yang berjalan pada aplikasi tersebut, apakah Marker/Barcode masing masing dapat menampilkan obek 3D dan suara pada aplikasi.. Hasil dari pegujian dapat di lihat pada Tabel 1.

Tabel 1 Pengujian Fungsional

\begin{tabular}{|c|c|c|c|c|c|c|}
\hline No & Produk & Uraian & $\begin{array}{l}\text { Loll } \\
\text { ypop } \\
(5.1)\end{array}$ & $\begin{array}{l}\text { Marsh } \\
\text { mellow } \\
(6.1)\end{array}$ & $\begin{array}{l}\text { Nou } \\
\text { ghat } \\
(7.1)\end{array}$ & $\begin{array}{l}\text { Oreo } \\
(8.1)\end{array}$ \\
\hline \multirow{5}{*}{1} & \multirow{5}{*}{ Produk 1} & Marker & $\checkmark$ & $\checkmark$ & $\checkmark$ & $\checkmark$ \\
\hline & & Audio & $\checkmark$ & $\checkmark$ & $\checkmark$ & $\checkmark$ \\
\hline & & Text & $\checkmark$ & $\checkmark$ & $\checkmark$ & $\checkmark$ \\
\hline & & $\begin{array}{l}\text { Model } \\
\text { 3D }\end{array}$ & $\checkmark$ & $\checkmark$ & $\checkmark$ & $\checkmark$ \\
\hline & & Rotasi & $\checkmark$ & $\checkmark$ & $\checkmark$ & $\checkmark$ \\
\hline \multirow{5}{*}{2} & \multirow{5}{*}{ Produk 2} & Marker & $\checkmark$ & $\checkmark$ & $\checkmark$ & $\checkmark$ \\
\hline & & Audio & $\checkmark$ & $\checkmark$ & $\checkmark$ & $\checkmark$ \\
\hline & & Text & $\checkmark$ & $\checkmark$ & $\checkmark$ & $\checkmark$ \\
\hline & & $\begin{array}{l}\text { Model } \\
\text { 3D }\end{array}$ & $\checkmark$ & $\checkmark$ & $\checkmark$ & $\checkmark$ \\
\hline & & Rotasi & $\checkmark$ & $\checkmark$ & $\checkmark$ & $\checkmark$ \\
\hline
\end{tabular}

Keterangan :

$\checkmark \quad=$ Berfungsi

$\boldsymbol{x}=$ Tidak berfungsi

Dari Tabel 1 di simpulkan bahwa semua fungsi marker berhasil di jalankan di masing masing sistem operasi android.

\subsubsection{Pengujian Jarak}

Jarak merupakan faktor yang berpengaruh langsung terhadap proses deteksi marker. Semakin jauh jarak marker terhadap kamera, maka semakin kecil ukuran dan kualitas pola marker yang dapat di proses oleh aplikasi. Pengujian jarak ini bertujuan untuk mengetahui rentang jarak yang optimal agar marker dapat terdeteksi dengan baik.

Pengujian di lakukan terhadap 3 rentangan jarak, yakni dekat $(10 \mathrm{~cm})$, sedang $(30 \mathrm{~cm})$, dan jauh $(60 \mathrm{~cm})$. Pada Gambar 9 menunjukan pengujian deteksi marker pada jarak dekat. Dapat di lihat bahwa marker dapat di deteksi tetapi model 3D yang dimunculkan tidak terlihat sepenuhnya jadi informasi yang dimunculkan tidak maksimal pada jarak $10 \mathrm{~cm}$.

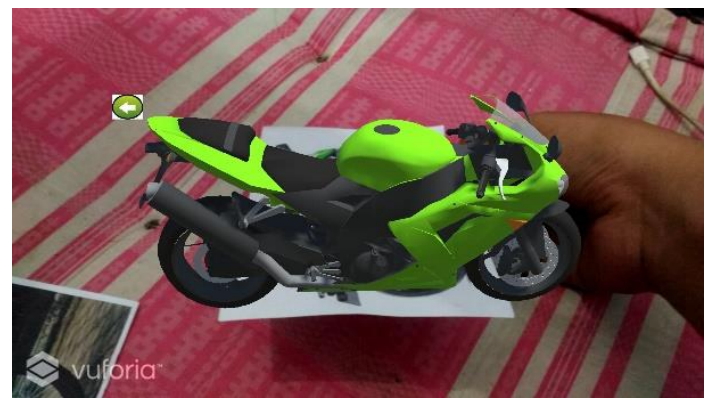

Gambar 9 Pengujian pada jarak dekat 
Pengujian berikutnya yakni pada rentang jarak sedang. Terlihat pada Gambar 10, marker dapat di deteksi dengan cukup baik pada jarak 30 $\mathrm{cm}$ dengan memunculkan objek 3D dan informasi berupa text dapat terbaca dengan jelas.

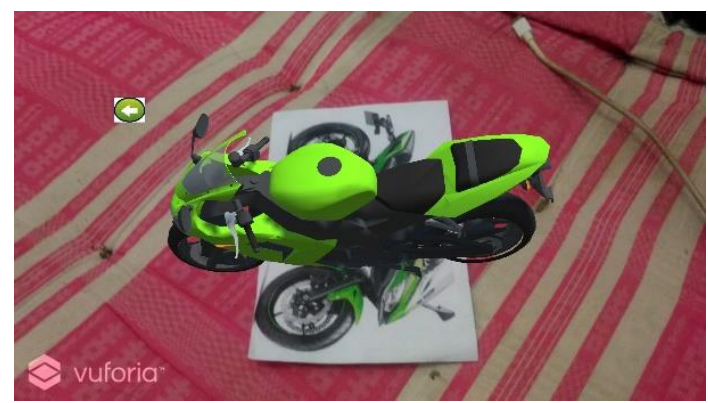

Gambar 10 Pengujian pada jarak sedang

Pengujian terakhir yakni pada rentang jarak jauh, pada jarak $10 \mathrm{~cm}$, aplikasi tidak dapat

Tabel 2 Tabel pengujian jarak mendeteksi marker dengan baik. Pada gambar 11 menunjukan marker masih dapat di deteksi pada jarak $60 \mathrm{~cm}$ tetapi informasi yang berupa text tidak dapat terbaca dikarenakan jarak yang terlalu jauh. dimana jarak ini merupakan jarak maximal untuk mendeteksi marker.

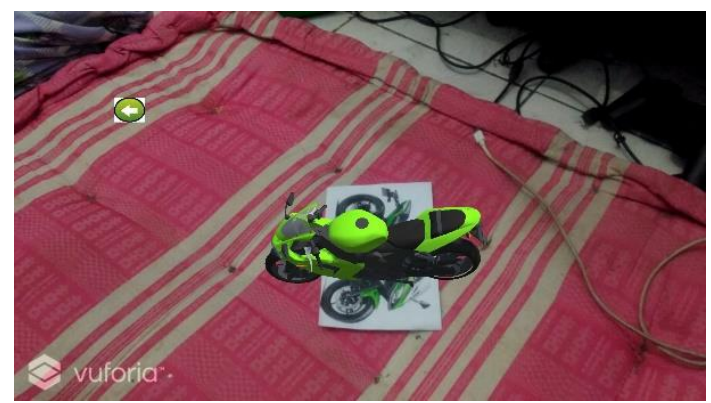

Gambar 11 Pengujian pada jarak jauh

\begin{tabular}{|c|c|c|c|c|c|c|}
\hline No & Produk & Uraian & $\begin{array}{c}\text { Lollypop } \\
(5.1)\end{array}$ & $\begin{array}{c}\text { Marshmellow } \\
(6.1)\end{array}$ & $\begin{array}{c}\text { Noughat } \\
(7.1)\end{array}$ & $\begin{array}{l}\text { Oreo } \\
(8.1)\end{array}$ \\
\hline \multirow{4}{*}{1} & \multirow{4}{*}{ Jarak dekat } & Marker & $\checkmark$ & $\checkmark$ & $\checkmark$ & $\checkmark$ \\
\hline & & Audio & $\checkmark$ & $\checkmark$ & $\checkmark$ & $\checkmark$ \\
\hline & & Model 3D & $\checkmark$ & $\checkmark$ & $\checkmark$ & $\checkmark$ \\
\hline & & Rotasi & $\checkmark$ & $\checkmark$ & $\checkmark$ & $\checkmark$ \\
\hline \multirow{4}{*}{2} & \multirow{4}{*}{ Jarak sedang } & Marker & $\checkmark$ & $\checkmark$ & $\checkmark$ & $\checkmark$ \\
\hline & & Audio & $\checkmark$ & $\checkmark$ & $\checkmark$ & $\checkmark$ \\
\hline & & Model 3D & $\checkmark$ & $\checkmark$ & $\checkmark$ & $\checkmark$ \\
\hline & & Rotasi & $\checkmark$ & $\checkmark$ & $\checkmark$ & $\checkmark$ \\
\hline \multirow{4}{*}{3} & \multirow{4}{*}{ Jarak jauh } & Marker & $\checkmark$ & $\checkmark$ & $\checkmark$ & $\checkmark$ \\
\hline & & Audio & $\checkmark$ & $\checkmark$ & $\checkmark$ & $\checkmark$ \\
\hline & & Model 3D & $\checkmark$ & $\checkmark$ & $\checkmark$ & $\checkmark$ \\
\hline & & Rotasi & $\checkmark$ & $\checkmark$ & $\checkmark$ & $\checkmark$ \\
\hline
\end{tabular}

Keterangan :

$\checkmark \quad=$ Berfungsi

$\times \quad=$ Tidak berfungsi

\section{KESIMPULAN DAN SARAN}

\subsection{Kesimpulan}

1. Pendeteksian marker berjalan cukup baik, namun perlu diperhatikan jarak dan focus kamera, semakin dekat kamera pada marker maka semakin baik, diaplikasi ini kamera dapat mendeteksi marker sampai jarak satu meter dengan kondisi pencahayaan yang cukup atau menggunakan lampu.

2. Pemanfaatan teknologi AR sudah sesuai dengan perancangan dan berhasil menampilkan dua buah objek 3D dan menampilkan informasi di masing-masing objek.

3. Aplikasi Display Produk Kawasaki ini dapat digunakan sebagai sarana untuk menarik minat konsumen untuk mengetahui informasi tentang produk yang diminati.

\subsection{Saran}

1. Model objek 3D masih kurang bagus dan diharapkan bisa di kembangkan lagi menjadi objek 3D yang lebih mendetail sebagai model AR agar konsumen lebih tertarik.

2. Diharapkan kedepannya bisa menggunakan virtual button agar tampilannya lebih menarik

\section{DAFTAR PUSTAKA}

[1] Yostab I Kadek, Crisnapati Padma Nyoman, Darmawiguna I Gede, Kesiman Made Windu. Augmented Reality Book Pengenalan Perangkat Gamelan Bali. Jurnal Nasional Pendidikan Teknik 
Informatika (JANAPATI) Vol. 3, No. 1. 2089-8673.

[2] Pratikno Heri. Kontrol Gerakan Objek 3D Augmented Reality Berbasis Titik Fitur Wajah dengan POSIT. JNTETI, Vol. 4, No.1. $2301-4156$.

[3] Saurina Nia. Pengembangan Media Pembelajaran Untuk Anak Usia Dini Menggunakan Augmented Reality. Jurnal IPTEK Vol.20 No.1. 1411-7010.

[4] Wahyudi Andria Kusuma. ARca, Pengembangan Buku Interaktif Berbasis Augmented Reality dengan Smartphone Android. JNTETI Vol. 3 No. 2. $2301-4156$

[5] Permana Fitri Yuliantri. Mempertahankan Pasar Media Cetak Melalui Konten Augmented Reality/AR. Channel, Vol. 5, No. 2. 23389176

[6] Ramdhan Khemal Rizky, Nurhasanah Youllia Indrawaty, Utoro Rio Korio. Aplikasi Media Pembelajaran Tulang Manusia Menggunakan Augmented Reality (AR) Berbasis Android. Jurnal Teknik Informatika dan Sistem Informasi Vol. 3 No.3. 2443-2229.
[7] Wahyutama Febrian, Samopa Febriliyan, Suryotrisongko Hatma. Penggunaan Teknologi Augmented Reality Berbasis Barcode sebagai Sarana Penyampaian Informasi Spesifikasi dan Harga Barang yang Interaktif Berbasis Android, Studi Kasus pada Toko Elektronik ABC Surabaya. JURNAL TEKNIK POMITS Vol. 2, No. 3. 2337-3539.

[8] Setiawan Erwin, Syaripudin Undang, Gerhana Yana Aditya. Implementasi Teknologi Augmented Reality Pada Buku Panduan Wudhu Berbasis Mobile Android. JOIN Vol. I No. 1. 2527-9165.

[9] Indriani Riana, Sugiarto Bayu, Purwanto Agus. Pembuatan Augmented Reality Tentang Pengenalan Hewan Untuk Anak Usia Dini Berbasis Android Menggunakan Metode Image Tracking Vuforia. 23023805.

[10] Saputra Yoga Aprillion. Implementasi Augmented Reality (AR) Pada Fosil Purbakala Di Museum Geologi Bandung. KOMPUTA Edisi. 1 Vol. 1. 